\title{
Sofosbuvir/velpatasvir regimen promises an effective pan-genotypic hepatitis $C$ virus cure
}

REVIEW

This article was published in the following Dove Press journal:

Drug Design, Development and Therapy

23 February 2017

Number of times this article has been viewed

Fazia Mir

Alp S Kahveci

Jamal A Ibdah

Veysel Tahan

Division of Gastroenterology and Hepatology, University of Missouri, Columbia, MO, USA

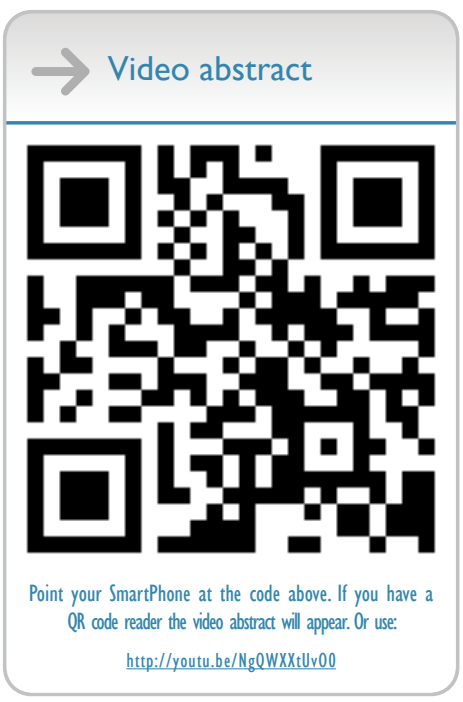

Correspondence: Veysel Tahan Division of Gastroenterology and Hepatology, University of Missouri Columbia, DC043.00, I Hospital Drive, Columbia, MO 6520I, USA

Tel +l 5738846044

Fax + I 5738844595

Email tahanv@health.missouri.edu
Abstract: Hepatitis C virus (HCV) is a global pandemic, with nearly 200 million infected patients worldwide. HCV is the most common blood-borne infection in the US with numerous health implications including liver fibrosis, cirrhosis, and hepatocellular cancer. Traditional genotype-based HCV therapies with interferon resulted in moderate success in the sustained elimination of viral genome. Recent clinical trials of the once-daily combination tablet of sofosbuvir, a nonstructural (NS) 5B polymerase inhibitor, and velpatasvir, an NS5A inhibitor, demonstrate sustained virologic response rates of about $95 \%$, regardless of prior treatment experience or presence of cirrhosis across all HCV genotypes. Patients reported improvements in general health, fatigue, and emotional and mental well-being after completing combination therapy. The combination treatment is effective, but does need to be administered with caution in patients receiving certain medications or with certain diseases. Herein, we review the safety and efficacy of sofosbuvir/velpatasvir combination regimen for all HCV genotypes.

Keywords: sofosbuvir, velpatasvir, hepatitis C, treatment, pan-genotypic, genotype

\section{Introduction}

Hepatitis $\mathrm{C}$ virus (HCV), a blood-borne virus responsible for inflammation, fibrosis, and cirrhosis of the liver, was first documented in $1989 .{ }^{1}$ It plagues nearly 200 million people worldwide out of which it is estimated that $16 \%$ of individuals develop compensated cirrhosis over a 20-year timeframe. ${ }^{2}$ Most patients with HCV have acquired the virus from either injection drug use or from nosocomial exposure (blood transfusions to hemophiliacs, infected health care workers) where strict blood screening guidelines were not adhered to. ${ }^{3} \mathrm{HCV}$ can be transmitted from one partner to another in heterosexual and homosexual couples, but the rate of transmission is higher in men who have sex with men, especially those men who have unprotected anal intercourse and have HIV. ${ }^{4}$ Transmission of HCV can be prevented by avoiding sharing of needles, tattooing done with strict sterilization techniques, condoms for men who have sex with men, and avoiding sharing toothbrushes and razors.

Acute HCV presents as jaundice in about $25 \%$ of patients. Some patients will present with nonspecific fatigue, malaise, or arthralgia. Over several decades, $20 \%-30 \% 5$ of the HCV population will develop compensated cirrhosis, which can progress to life-threatening decompensated cirrhosis or hepatocellular carcinoma (HCC), obviating the need for liver transplantation for preventing further complications from cirrhosis. Extrahepatic manifestations are often associated with chronic HCV infection and include cryoglobulinemia, porphyria cutanea tarda, membranoproliferative glomerulonephritis, Sjogren's syndrome, idiopathic thrombocytopenic purpura, and 
non-Hodgkin's lymphoma. ${ }^{6}$ Progression of HCV cirrhosis to $\mathrm{HCC}$ has been reported to be as high as 3\%-5\% annually. ${ }^{7}$

Screening for HCV should be done by primary care physicians, to prevent further transmission of the infection, as the acute and chronic phases for HCV are asymptomatic. Screening has been shown to be cost-effective. ${ }^{8}$

Worldwide, out of $6 \mathrm{HCV}$ genotypes, type 1 (specifically subtype 1a) is the most common. Genotypes 1-3 are prevalent throughout the US, Japan, and Europe, while genotypes 4-6 cause infection in North Africa, South Africa, and Southeast Asia, respectively. ${ }^{9}$ Most genotypes have similar liver disease manifestations, with the exception of genotype 3 , which does cause hepatic steatosis. ${ }^{10}$ Historically, treatment regimens focused upon pegylated-interferon $(\mathrm{Peg}-\mathrm{IFN})^{11}$ and later a combination with ribavirin, ${ }^{12}$ but at present, the treatment available for hepatitis $\mathrm{C}$ targets $\mathrm{HCV}$ proteins. However, sustained virologic response (SVR) rates have proved problematic and inconsistent across genotypes with the traditional therapy, ${ }^{12,13}$ especially those involving hard-to-cure genotype 3 and/or cirrhosis. More often than not, patients developed adverse effects, including neuropsychiatric symptoms, flu-like syndromes, gastrointestinal upsets, and insomnia. ${ }^{14}$

The breakthrough of direct-acting antivirals (DAAs) in 2011 provided a window of opportunity to substantially elevate SVR rates across all genotypes and subtypes, regardless of treatment experience and cirrhotic factors. The DAAs had an improved safety profile, fewer side effects, better tolerability, and shortened treatment duration with prolonged SVR. The driving force behind DAAs was the identification and targeting of the nonstructural proteins (p7, NS2, NS3, NS4A, NS4B, NS5A, and NS5B) involved in the replication of the HCV genome. ${ }^{15}$ As such, three main drug classes emerged: NS5A inhibitors, NS5B polymerase inhibitors (PIs), and NS3/4A protease inhibitors. ${ }^{2}$ While first-generation DAAs were approved in joint usage with Peg-IFN and ribavirin, the current treatment regimens have moved away from Peg-IFN. At the forefront of these treatments lies the potent fixed drug combination of sofosbuvir, an NS5B PI, and velpatasvir, an NS5A inhibitor (Epclusa, Gilead Sciences, Foster City, CA, USA). In the ASTRAL-1 trial, once-daily sofosbuvir $400 \mathrm{mg} /$ velpatasvir $100 \mathrm{mg}$ given for 12 weeks was reported to have $99 \%$ efficacy across genotypes $1-6$ in both treatmentnaive and experienced patients. Two percent of patients out of the 624 treated reported serious adverse effects pertaining to the administered medication. ${ }^{16}$ In this review, we discuss the safety, efficacy, and tolerability of the sofosbuvir and velpatasvir pan-genotypic treatment combination.

\section{NS protein inhibitors}

As a second-generation NS5A inhibitor, it is widely believed that velpatasvir inhibits hepatitis $\mathrm{C}$ viral replication through acting on the crucial "membranous web" that facilitates RNA replication. ${ }^{17}$ Velpatasvir is highly bound to plasma protein and undergoes hepatic excretion where it is metabolized by the cytochrome P450 enzyme within the liver. ${ }^{18}$ Sofosbuvir is a uridine nucleoside analog inhibitor that targets RNA polymerase, thereby preventing the binding and incorporation of nucleoside triphosphates into mRNA. ${ }^{19}$ Extensively metabolized in the liver, sofosbuvir undergoes dephosphorylation into its inactive form, GS-331007. Unlike velpatasvir, sofosbuvir is roughly $60 \%$ bound to plasma proteins. Moreover, the greater portion of sofosbuvir is renally excreted. ${ }^{18}$

\section{Pan-genotypic}

In the first of several ASTRAL studies, Feld et al ${ }^{16}$ conducted a phase 3, double-blind, placebo-controlled 12-week study involving 624 chronic $\mathrm{HCV}$ patients from across the globe representing genotypes $1,2,4,5$, and 6 . Patients were randomly assigned to the treatment group (a once-daily combination tablet of $400 \mathrm{mg}$ sofosbuvir and $100 \mathrm{mg}$ velpatasvir) or a placebo. At 12 weeks posttherapy, HCV RNA levels were measured to assess treatment efficacy as defined by an SVR-12 rate above $85 \%$. Profiles of patients assigned to the treatment group included compensated cirrhosis (19\%), prior treatment experience (32\%), which primarily included a Peg-IFN therapy ( $89 \%$ ), and a mean age of 54 years. Feld et $\mathrm{al}^{16}$ reported significantly high SVR rates across all patient populations, whether treatment-naïve or experienced. While the patients assigned to the placebo group elicited no SVR, those assigned to the joint sofosbuvir/velpatasvir therapy had a remarkable $99 \%$ SVR. The drug combination was effective in all the HCV genotypes, with SVR rates of 100\% among genotypes 2, 4, and 6, 99\% among genotype $1 \mathrm{~b}, 98 \%$ among genotype 1a, and $97 \%$ among genotype $5 .{ }^{20}$ Moreover, SVR rates remained high irrespective of whether the patients had cirrhosis and whether they had received previous therapy. ${ }^{16}$ Though the primary aim was to assess efficacy, treatment safety was documented through rate of adverse effects and patient-reported outcomes. Only 2 patients receiving treatment, both of whom were infected with genotype 1 , had a virologic failure, while roughly $2 \%$ of all patients had serious adverse side effects. Furthermore, sofosbuvir/velpatasvir treatment did not increase susceptibility to adverse health events. ${ }^{20}$

To better understand the health-related quality of life, impact on fatigue, and work productivity following 
HCV therapy, Younossi et $\mathrm{al}^{21}$ periodically collected self-administered questionnaires from patients during and after the study. The questionnaires represented a wide spectrum of physiological and psychological domains. A statistically significant improvement in general health, emotional well-being, activity/energy, anxiety, and physical functioning was noted as the study progressed. ${ }^{21}$ By completion of therapy, follow-up questionnaires at 24 weeks after treatment cessation reported increase in the same domains with additional improvements in bodily pain, social functioning, mental health, fatigue, and attendance at work. Patients in the placebo arm did not report improvements in the quality of life by completion of therapy.

These results lent credence to the superior efficacy and safety of the combination sofosbuvir/velpatasvir therapy for $\mathrm{HCV}$ patients with and without cirrhosis.

\section{Difficult-to-cure populations}

In order to address potentially difficult-to-cure populations, Foster et al, ${ }^{22}$ along with ASTRAL-2 and ASTRAL-3 investigators, conducted two randomized, phase 3, open-label studies. They enrolled genotype 2 or 3 patients with and without treatment experience and with and without cirrhosis. ${ }^{22}$ Patients were separated based on genotype and randomly assigned to two treatment groups: a once-daily combination tablet of $400 \mathrm{mg}$ sofosbuvir and $100 \mathrm{mg}$ velpatasvir for 12 weeks or $400 \mathrm{mg}$ of sofosbuvir plus weight-based ribavirin for either 12 or 24 weeks. Patients with genotype 2 in the sofosbuvir/velpatasvir combination tablet treatment arm achieved a 99\% SVR. Sofosbuvir plus weight-based ribavirin combination for 12 weeks is an alternative regimen for genotype $2 \mathrm{HCV}$ patients without cirrhosis with an achievement of SVR in $94 \%$ of cases. This same regimen can be applied to genotype $3 \mathrm{HCV}$ patients with $80 \% \mathrm{SVR}$ achievement and similar tolerability despite extended treatment duration of 24 weeks in this group of patients. ${ }^{22}$ In the ASTRAL-3 trial, genotype 3 treatment-naive and experienced patients were separated into two treatment arms, with one group receiving 12 weeks of daily sofosbuvir/velpatasvir and the other group receiving 24 weeks of sofosbuvir plus weightbased ribavirin. In the sofosbuvir/velpatasvir arm, 95\% of genotype 3 patients achieved SVR (95\% CI, 92\%-98\%) compared with $80 \%$ of SVR achievement (CI, 75\%-85\%) in the sofosbuvir and weight-based ribavirin group.

Efficacy in cirrhotic patients was also evaluated with cirrhotics in the sofosbuvir/velpatasvir group, and they achieved a $91 \%$ SVR compared with a $66 \%$ SVR in the sofosbuvir/ribavirin group. ${ }^{22}$ Adverse health events (Table 1)
Table I Adverse effects with sofosbuvir/velpatasvir combination from ASTRAL I, 2, 3 trials

\begin{tabular}{|c|c|}
\hline Adverse effect & Recommendation \\
\hline Headache & $\begin{array}{l}\text { Seen in } 22 \% \text { of patients; usually mild and } \\
\text { tolerable. }\end{array}$ \\
\hline Fatigue & Seen in $15 \%$ of patients; mild. \\
\hline Nausea & Seen in $9 \%$ of patients; mild. \\
\hline Asthenia & Seen in $5 \%$ of patients. \\
\hline Insomnia & Seen in $5 \%$ of patients; usually mild. \\
\hline Bradycardia & $\begin{array}{l}\text { Avoid concomitant administration with } \\
\text { amiodarone. }\end{array}$ \\
\hline Anemia & $\begin{array}{l}\text { Seen in } 26 \% \text { of patients when given with } \\
\text { ribavirin in decompensated cirrhotics. Monitor } \\
\text { hemoglobin. If hemoglobin is below } 8 \mathrm{~g} / \mathrm{dL} \text {, } \\
\text { titrate dose of ribavirin or stop it completely. }\end{array}$ \\
\hline Rash & $\begin{array}{l}\text { Seen in } 2 \% \text { of patients and of mild to moderate } \\
\text { severity. }\end{array}$ \\
\hline Depression & $\begin{array}{l}\text { Seen in I\% of patient population and of mild } \\
\text { severity. }\end{array}$ \\
\hline Lipase levels & $\begin{array}{l}\text { Asymptomatic lipase elevations (up to } 3 \times \text { ULN) } \\
\text { may be seen with combination therapy; monitor. }\end{array}$ \\
\hline Indirect bilirubin & $\begin{array}{l}\text { Asymptomatic increase up to } 3 \mathrm{mg} / \mathrm{dL} \text { may be } \\
\text { seen with coadministration with antiretroviral } \\
\text { drugs for } \mathrm{HIV/HCV} \text { coinfected patients. }\end{array}$ \\
\hline
\end{tabular}

Note: Data from Feld et al, ${ }^{16}$ Foster et al, ${ }^{22}$ and Younossi et al. ${ }^{23}$

Abbreviations: HCV, hepatitis C virus; ULN, upper limit of normal.

were more likely to occur in the sofosbuvir/ribavirin group than in the sofosbuvir/velpatasvir group (71.3\% vs 52.3\%). At present, there is no dosage adjustment required for sofosbuvir in patients with chronic kidney disease or creatinine clearance less than $30 \mathrm{~mL} / \mathrm{min}$. As was the case with the ASTRAL-1 study, Younossi et $\mathrm{al}^{23}$ documented patientreported outcomes during and after therapy. Four weeks into the treatment, statistically and clinically significant improvements were observed in many of the prodomains among sofosbuvir/velpatasvir treated patients, including physical and emotional well-being, bodily pain, and general health. ${ }^{23}$ Sofosbuvir/ribavirin therapy yielded varying results, with patients reporting increased body aches, poorer emotional health, and well-being. Patients also reported impaired social functioning and physical well-being, decreased below the baseline level. The immediate benefits provided by sofosbuvir/velpatasvir to whole-body health, especially difficult-to-cure genotype 3 patients, was superior to the sofosbuvir plus weight-based ribavirin therapy.

\section{Decompensated cirrhosis}

The annual progression rate of compensated cirrhosis to decompensated cirrhosis is estimated at $3 \%-6 \%$. $^{2}$ The prevalence of decompensated cirrhosis is expected to rise until 2030, which will most likely result in an increase in the number of liver transplantations. ${ }^{24}$ Treatment with sofosbuvir/velpatasvir 
may help delay the progression to cirrhosis by achieving cure from the HCV. A phase 3, open-label trial conducted by Curry et $\mathrm{al}^{25}$ enrolled Child-Turcotte-Pugh (CTP) class B patients with genotypes 1, 2, 3, 4, and 6. Similar to the design of the ASTRAL-2 and ASTRAL-3 study, patients were randomly assigned to $400 \mathrm{mg}$ sofosbuvir-100 mg velpatasvir, or $400 \mathrm{mg}$ sofosbuvir/velpatasvir plus weight-based ribavirin. Of the 267 enrolled, slightly over half were treatment-experienced, and none had been treated previously with an NS5A or NS5B inhibitor. Of the patients who received sofosbuvir/velpatasvir, $83 \%$ and $86 \%$ achieved an SVR following 12 and 24 weeks of treatment, respectively. ${ }^{25}$ Interestingly, the addition of ribavirin to the sofosbuvir/velpatasvir therapy yielded a much higher SVR rate, 94\%. However, these differences in SVR rates were not statistically significant. The ASTRAL-3 studies did not show superior results of sofosbuvir/ribavirin treatment; the potential benefit of adding ribavirin to the Food and Drugs Administration-approved combination tablet of sofosbuvir/velpatasvir must be considered. On its own, sofosbuvir/velpatasvir for either duration $(12,24$ weeks ) had a 50\% SVR rate among genotype 3 patients with decompensated cirrhosis, but with the addition of weight-based ribavirin, the SVR rate rose to $85 \% .{ }^{25}$ The DAAs improved liver function tests in the treated patient population. From an average baseline CTP score of $8,47 \%$ of patients had improved at least 1 point in their CTP score, while $42 \%$ remained stable. ${ }^{25}$ Feld and Zeuzem ${ }^{20}$ and Foster et al, ${ }^{22}$ in their safety results data, noted that decompensated cirrhotic patients were more susceptible to serious adverse health events. Patients treated with sofosbuvir/velpatasvir for 12 weeks or 24 weeks or for
12 weeks with ribavirin experienced serious adverse health events approximately $20 \%$ of the times. Similar to the other ASTRAL studies, fatigue and nausea were common adverse health events.

\section{Genotype 7}

In an addendum to the ASTRAL-1 investigation, a missequenced patient was later determined to have HCV genotype 7 following treatment with sofosbuvir/ velpatasvir. Originating from the Democratic Republic of Congo, genotype 7 has only been documented in a few individuals. ${ }^{26,27}$ Nonetheless, this patient achieved a SVR, once more highlighting the pan-genotypic ability of the potent combination. ${ }^{27}$

\section{Drug-drug interactions}

Potential drug-drug interactions between sofosbuvir and velpatasvir were evaluated in an open-label study. Eighteen non-HCV, healthy individuals were enrolled, and there were no clinically significant drug-drug interactions reported in this study by Mogalian et al. ${ }^{28}$ When administering sofosbuvir or sofosbuvir-containing regimens, patients should be cautioned to avoid rifampin, St John's wort, or tipranavir because these agents decrease the efficacy of sofosbuvir by decreasing circulating drug levels of sofosbuvir (Table 2). Velpatasvir can have decreased absorption if the patient is on concomitant antacids and acid-reducing medications. Patients should be asked to report all medications they are currently on and if they are going to start on any additional medications including over-the-counter medications or herbal supplements.

Table 2 Drug-drug interactions with sofosbuvir/velpatasvir combination regimen

\begin{tabular}{|c|c|}
\hline Medication & Recommendations \\
\hline Rifampin, rifabutin, rifapentein & Not recommended. \\
\hline Statins & Rosuvastatin dose should be $10 \mathrm{mg}$ daily while on combination therapy. \\
\hline Phenytoin, phenobarbital, carbamazepine, oxcarbazepine & Not recommended. \\
\hline Histamine receptor blockers and PPIs & $\begin{array}{l}\text { PPIs effect decreased when SOF/VEL is given with food. Can use omeprazole } \\
20 \mathrm{mg} 4 \text { hours after taking SOF/VEL. Other PPIs have not been studied. Use } \\
\text { famotidine } 40 \mathrm{mg} \text { twice daily or comparable dose with other } \mathrm{H} 2 \text { receptor blockers. }\end{array}$ \\
\hline Efavirenz & Not recommended as can decrease efficacy of combination regimen. \\
\hline Digoxin & Has narrow therapeutic index; needs to be monitored. \\
\hline Oral contraceptives & Can be administered concomitantly. \\
\hline Etravirine, nevirapine rilpivirine, rilpivirine & No dose adjustment needed. \\
\hline $\begin{array}{l}\text { Dolutegravir, elvitegravir/cobicistat/tenofovir alafenamide/ } \\
\text { emtricitabine combination, raltegravir, rlvitegravir/cobicistat/ } \\
\text { tenofovir disoproxil fumarate/emtricitabine }\end{array}$ & $\begin{array}{l}\text { No dosage adjustment needed. With tenofovir, monitor for renal side effects as } \\
\text { SOF/VEL combination can potentially increase tenofovir levels. }\end{array}$ \\
\hline Herbal products - St John's Wort & Not recommended as can decrease efficacy of combination regimen. \\
\hline Amiodarone & $\begin{array}{l}\text { Not recommended as can cause significant bradycardia if used concurrently. } \\
\text { Cardiac monitoring is recommended if needs to be used. }\end{array}$ \\
\hline Antacids & Separate antacids and SOF/VEL administration by 4 hours. \\
\hline
\end{tabular}

Abbreviations: SOF/VEL, sofosbuvir/velpatasvir; PPIs, proton pump inhibitors. 


\section{HCV relapse}

$\mathrm{HCV}$ relapse on sofosbuvir is usually secondary to reexposure to the virus after achieving SVR. Relapses, after using sofosbuvir for therapy, are unlikely to have a virus with resistant variants. Therefore, sofosbuvir can be successfully used to re-treat the same individual who has previously received treatment with sofosbuvir in combination with another alternate antiviral. ${ }^{29}$ In relapsed genotype 3 patients, there was an emergence of $\mathrm{Y} 93 \mathrm{H}$ baseline variant; therefore, it may be prudent to add weight-based ribavirin to this group with the combination therapy of sofosbuvir and velpatasvir. ${ }^{30}$

\section{Conclusion}

The introduction of DAAs to selectively target the HCV replication process has yielded a plethora of scientific research, with promising results at each end. Thus far, the potent combination of sofosbuvir, an NS5B PI, and velpatasvir, an NS5A inhibitor, has shown $>94 \%$ SVR rates among all major HCV genotypes, including the difficultto-cure genotypic, cirrhotic, and treatment-experienced populations (Table 3). The virologic cure is a possibility with this regimen as SVR rates have been reported at or above $95 \%$. In addition to improvements in general health, emotional and mental well-being and social productivity throughout therapy and posttherapy in a sizeable number of patients illustrate the efficacy of the combination treatment. Currently, pretreatment genotype testing and stage of liver disease fibrosis determine which patients will receive therapy for HCV by the insurance companies. ${ }^{31}$ The pan-genotypic success achieved with sofosbuvir/velpatasvir makes therapy

Table 3 Sofosbuvir and velpatasvir for treatment-naïve and experienced patients

\begin{tabular}{|c|c|c|}
\hline $\begin{array}{l}\text { Treatment } \\
\text { stage }\end{array}$ & Genotype & Recommendation \\
\hline $\begin{array}{l}\text { Initial treatment } \\
\text { of chronic } \\
\text { hepatitis C }\end{array}$ & $I, 2,3,4,5,6$ & $\begin{array}{l}\text { I } 2 \text { weeks treatment duration for } \\
\text { patients with genotypes I-6, including } \\
\text { patients with compensated cirrhosis }\end{array}$ \\
\hline $\begin{array}{l}\text { Retreatment } \\
\text { of chronic } \\
\text { hepatitis C }\end{array}$ & $I, 2,3,4,5,6$ & $\begin{array}{l}\text { Treatment experienced, including } \\
\text { compensated cirrhosis with HCV } \\
\text { genotypes Ia, Ib, and } 2 \text {, will have } \\
\text { I } 2 \text { weeks of therapy }\end{array}$ \\
\hline & & $\begin{array}{l}\text { HCV genotype } 3: 24 \text { weeks total } \\
\text { treatment duration with weight-based } \\
\text { ribavirin regardless of cirrhosis state } \\
\text { HCV genotypes } 4,5,6: \text { treatment } \\
\text { experienced, including compensated } \\
\text { cirrhotics, need I } 2 \text { weeks with } \\
\text { weight-based ribavirin }\end{array}$ \\
\hline
\end{tabular}

Abbreviation: $\mathrm{HCV}$, hepatitis $\mathrm{C}$ virus. simple, safe, and curative, but access to therapy is limited by cost. Once therapy is accessible to all patients, this will decrease health care disease burden with a resultant decrease in morbidity and mortality, and then patients can be cured from the $\mathrm{HCV}$ virus without having to undergo pregenotype testing.

Further trials are still needed with the DAAs for hepatitis $\mathrm{C}$ to be able to be used in complex patient populations with HIV, diabetes mellitus, or cardiovascular diseases and further prolong the SVR.

\section{Author contributions}

The first two authors contributed equally to the preparation of the manuscript. All authors contributed to the acquisition of data, writing, and revision of the manuscript. All authors approved the final version of the manuscript.

\section{Disclosure}

The authors report no conflicts of interest in this work.

\section{References}

1. Choo QL, Kuo G, Weiner AJ, Overby LR, Bradley DW, Houghton M Isolation of a cDNA clone derived from a blood-borne non-A, non-B viral hepatitis genome. Science. 1989;244(4902):359-362.

2. Majumdar A, Kitson MT, Roberts SK. Systematic review: current concepts and challenges for the direct-acting antiviral era in hepatitis $C$ cirrhosis. Aliment Pharmacol Ther. 2016;43(12):1276-1292.

3. Suryaprasad AG, White JZ, Xu F, et al. Emerging epidemic of hepatitis C virus infections among young nonurban persons who inject drugs in the United States, 2006-2012. Clin Infect Dis. 2014;59(10):1411-1419.

4. Wilkin T. CLINICAL PRACTICE. Primary care for men who have sex with men. $N$ Engl J Med. 2015;373(9):854-862.

5. Thomas DL, Astemborski J, Rai RM, et al. The natural history of hepatitis $\mathrm{C}$ virus infection: host, viral, and environmental factors. JAMA. 2000;284(4):450-456

6. Liang TJ, Rehermann B, Seeff LB, Hoofnagle JH. Pathogenesis, natural history, treatment, and prevention of hepatitis C. Ann Intern Med. 2000 132(4):296-305.

7. Degos F, Christidis C, Ganne-Carrie N, et al. Hepatitis C virus related cirrhosis: time to occurrence of hepatocellular carcinoma and death. Gut. 2000;47(1):131-136.

8. Rein DB, Smith BD, Wittenborn JS, et al. The cost-effectiveness of birth-cohort screening for hepatitis C antibody in U.S. primary care settings. Ann Intern Med. 2012;156(4):263-270.

9. Scheel TK, Rice CM. Understanding the hepatitis $C$ virus life cycle paves the way for highly effective therapies. Nat Med. 2013;19(7):837-849.

10. Tapper EB, Afdhal NH. Is 3 the new 1: perspectives on virology, natural history and treatment for hepatitis C genotype 3. J Viral Hepat. 2013 20(10):669-677.

11. Feuerstadt P, Bunim AL, Garcia H, et al. Effectiveness of hepatitis $C$ treatment with pegylated interferon and ribavirin in urban minority patients. Hepatology. 2010;51(4):1137-1143.

12. Zeuzem S, Feinman SV, Rasenack J, et al. Peginterferon alfa-2a in patients with chronic hepatitis C. N Engl J Med. 2000;343(23):1666-1672.

13. Yang JF, Kao YH, Dai CY, et al. Comparison of adverse effects related to pegylated interferon-based therapy for patients with chronic hepatitis B and chronic hepatitis C in Taiwan. Hepatol Int. 2010;4(4) 732-740. 
14. Manns MP, McHutchison JG, Gordon SC, et al. Peginterferon alfa-2b plus ribavirin compared with interferon alfa-2b plus ribavirin for initial treatment of chronic hepatitis C: a randomised trial. Lancet. 2001; 358(9286):958-965.

15. Berger C, Romero-Brey I, Radujkovic D, et al. Daclatasvir-like inhibitors of NS5A block early biogenesis of hepatitis $\mathrm{C}$ virus-induced membranous replication factories, independent of RNA replication. Gastroenterology. 2014;147(5):1094-1105.e25.

16. Feld JJ, Jacobson IM, Hezode C, et al. Sofosbuvir and velpatasvir for HCV genotype 1, 2, 4, 5, and 6 infection. NEngl J Med. 2015;373(27): 2599-2607.

17. Smolders EJ, de Kanter CT, van Hoek B, Arends JE, Drenth JP, Burger DM. Pharmacokinetics, efficacy, and safety of hepatitis C virus drugs in patients with liver and/or renal impairment. Drug Saf. 2016; 39(7):589-611.

18. Powdrill MH, Bernatchez JA, Gotte M. Inhibitors of the hepatitis $\mathrm{C}$ virus RNA-dependent RNA polymerase NS5B. Viruses. 2010;2(10): 2169-2195.

19. Moradpour D, Brass V, Gosert R, Wolk B, Blum HE. Hepatitis C: molecular virology and antiviral targets. Trends Mol Med. 2002;8(10): 476-482.

20. Feld JJ, Zeuzem S. Sofosbuvir and velpatasvir for patients with HCV infection. N Engl J Med. 2016;374(17):1688-1689.

21. Younossi ZM, Stepanova M, Feld J, et al. Sofosbuvir and velpatasvir combination improves outcomes reported by patients with HCV infection, without or with compensated or decompensated cirrhosis. Clin Gastroenterol Hepatol. 2016; pii: S1542-3565(16)31050-31053.

22. Foster GR, Afdhal N, Roberts SK, et al. Sofosbuvir and velpatasvir for HCV genotype 2 and 3 infection. N Engl J Med. 2015;373(27): 2608-2617.

23. Younossi ZM, Stepanova M, Sulkowski M, et al. Ribavirin-free regimen with sofosbuvir and velpatasvir is associated with high efficacy and improvement of patient-reported outcomes in patients with genotypes 2 and 3 chronic hepatitis $\mathrm{C}$ : results from Astral-2 and -3 clinical trials. Clin Infect Dis. 2016;63(8):1042-1048.
24. Davis GL, Alter MJ, El-Serag H, Poynard T, Jennings LW. Aging of hepatitis $\mathrm{C}$ virus ( $\mathrm{HCV}$ )-infected persons in the United States: a multiple cohort model of HCV prevalence and disease progression. Gastroenterology. 2010;138(2):513-521, 521.e1-e6.

25. Curry MP, O'Leary JG, Bzowej N, et al. Sofosbuvir and velpatasvir for $\mathrm{HCV}$ in patients with decompensated cirrhosis. N Engl J Med. 2015; 373(27):2618-2628.

26. Messina JP, Humphreys I, Flaxman A, et al. Global distribution and prevalence of hepatitis C virus genotypes. Hepatology. 2015;61(1): 77-87.

27. Schreiber J, McNally J, Chodavarapu K, Svarovskaia E, Moreno C. Treatment of a patient with genotype 7 hepatitis $\mathrm{C}$ virus infection with sofosbuvir and velpatasvir. Hepatology. 2016;64(3):983-985.

28. Mogalian E, German P, Brainard D, et al. Lack of a clinically significant pharmacokinetic drug-drug interaction between sofosbuvir and GS-5816 in healthy volunteers. Presented at: The Liver Meeting 2013: 64th Annual Meeting of the American Association for the Study of Liver Diseases; November 1-5; 2013; Washington, DC.

29. Osinusi A, Kohli A, Marti MM, et al. Re-treatment of chronic hepatitis C virus genotype 1 infection after relapse: an open-label pilot study. Ann Intern Med. 2014;161(9):634-638.

30. Hezode C. Pan-genotypic treatment regimens for hepatitis $\mathrm{C}$ virus: advantages and disadvantages in high- and low-income regions. J Viral Hepat. 2017;24(2):92-101.

31. Ward JW, Mermin JH. Simple, effective, but out of reach? Public health implications of HCV drugs. $N$ Engl J Med. 2015;373(27): $2678-2680$
Drug Design, Development and Therapy

\section{Publish your work in this journal}

Drug Design, Development and Therapy is an international, peerreviewed open-access journal that spans the spectrum of drug design and development through to clinical applications. Clinical outcomes, patient safety, and programs for the development and effective, safe, and sustained use of medicines are the features of the journal, which

\section{Dovepress}

has also been accepted for indexing on PubMed Central. The manuscript management system is completely online and includes a very quick and fair peer-review system, which is all easy to use. Visit http://www.dovepress.com/testimonials.php to read real quotes from published authors. 